Artigo original

Hegemonia - Revista Eletrônica do Programa de Mestrado em Direitos Humanos, Cidadania e Violência/Ciência Política do Centro Universitário Unieuro

ISSN: $1809-1261$

UNIEURO, Brasília, número 24, Julho a Dezembro de 2018, pp. 24-43.

Recebido em: 6/12/2017

Avaliado em: 27/1/2018

Aprovado em: 24/4/2018

\title{
A IDEOLOGIA NOS DICIONÁRIOS: UMA ANÁLISE DOS VERBETES CAPITALISMO E COMUNISMO
}

Delmo de Oliveira Arguelhes ${ }^{1}$ e Demétrio Pires Weber Candiota da Rosa ${ }^{2}$

RESUMO: Neste artigo, é analisada a ideologia presente em dicionários, a partir do exame dos significados atribuídos aos vocábulos capitalismo e comunismo. Dicionários, por natureza, buscam a objetividade em suas definições. Por isso mesmo, constituem espaço privilegiado de análise das formas como a ideologia dominante penetra nas estruturas mais profundas de representação da realidade.

PALAVRAS-CHAVE: Ideologia. Objetividade. Capitalismo. Comunismo.

ABSTRACT: This article analyzes the ideology present in dictionaries from the examination of the meanings attributed to the words capitalism and communism. Dictionaries by nature seek objectivity in their definitions. For this reason they constitute a privileged space of analysis of the ways in which the dominant ideology penetrates the deeper structures of representation of reality.

KEYWORDS: Ideology. Objectivity. Capitalism. Communism.

\section{Introdução}

Ao reunir em suas páginas milhares de vocábulos, com a tarefa de apontar os principais significados de cada palavra, os dicionários influenciam e delimitam o uso das línguas. Servem de referência para os complexos processos de representação da

\footnotetext{
${ }^{1}$ Doutor em História das Ideias, pesquisador de pós doutorado no INEST/UFF e professor do Mestrado em Direitos Humanos, Cidadania e Violência no Centro Universitário UNIEURO.

${ }^{2}$ Mestre em Direitos Humanos, Cidadania e Violência no Centro Universitário UNIEURO., mestrando em Direitos Humanos, Cidadania e Violência no Centro Universitário UNIEURO.
} 
Artigo original

Hegemonia - Revista Eletrônica do Programa de Mestrado em Direitos Humanos, Cidadania e Violência/Ciência Política do Centro Universitário Unieuro

ISSN: $1809-1261$

UNIEURO, Brasília, número 24, Julho a Dezembro de 2018, pp. 24-43.

realidade, pelos quais a linguagem estabelece as bases da comunicação, da construção do saber e das relações de poder.

Como toda obra humana, os dicionários refletem e, ao mesmo tempo, contribuem para moldar visões de mundo, valores e ideologias. Não é desprezível o papel que exercem na disseminação de normas e conceitos. Por conseguinte, nas disputas de poder.

Evidentemente, cada idioma é uma construção coletiva: a atividade dos lexicógrafos está submetida a uma série de constrangimentos. Logo, os dicionaristas não têm a liberdade de inventar significados, pois devem se ater aos usos (e abusos) da língua pela comunidade de usuários.

Por um lado, enfrentam o desafio de resumir, de maneira objetiva, os significados empregados pelo universo de falantes. Devem buscar na história e na realidade social as definições que registrarão a cada verbete.

Por outro, servem de referência, ao difundir as regras ortográficas e apontar as mais frequentes possibilidades de uso de cada vocábulo. Mesmo que indiretamente, interferem nos debates e embates travados por meio do idioma.

Quem abre as páginas de um dicionário espera encontrar a maior objetividade possível. Isenção e exatidão são características mais do que desejáveis. Eis o que faz dessas publicações espaço privilegiado para se analisar como a ideologia dominante alcança as estruturas mais profundas de representação do real.

Se a ideologia pode ser definida como forma de consciência social que estrutura nossa percepção da realidade, não haveria por que os dicionários escaparem de sua influência.

O presente artigo lança um olhar sobre a ideologia que perpassa a elaboração de dicionários. Para isso, foram selecionados dois verbetes - capitalismo e comunismo -, com o objetivo de verificar o que pode haver de ideológico nas definições observadas. A escolha não foi fortuita: levou em conta que os dois vocábulos remetem a sistemas antagônicos de organização social e econômica, cerne de disputas ideológicas, políticas e bélicas no Brasil e no mundo.

Dada a autoridade de que desfrutam como referência ortográfica e semântica, não há dúvida de que os dicionários exercem tremenda influência sobre a formação dos indivíduos. Perceber em que medida tais publicações estão submetidas a 
Artigo original

Hegemonia - Revista Eletrônica do Programa de Mestrado em Direitos Humanos, Cidadania e Violência/Ciência Política do Centro Universitário Unieuro

ISSN: $1809-1261$

UNIEURO, Brasília, número 24, Julho a Dezembro de 2018, pp. 24-43.

vieses ideológicos pode ser extremamente útil na construção e consolidação de sociedades democráticas e plurais.

II. Conservador, liberal e revolucionário

Analisar a ideologia presente em dicionários foi o ponto de partida do filósofo húngaro István Mészáros (1930-2017), em O poder da ideologia. No caso, ele se debruçou sobre um dicionário eletrônico de sinônimos e comparou os resultados apresentados para três adjetivos: conservador, liberal e revolucionário.

A lista de sinônimos dos dois primeiros - conservador e liberal - era extensa e recheada de qualidades, como 'de bom gosto' e 'equilibrado' (conservador) ou 'generoso' e 'avançado' (liberal), ao passo que os sinônimos para revolucionário apareciam em menor número e incluíam termos como 'enfurecido', 'extremista' e 'fanático'.

É a partir desse flagrante de parcialidade - justo em um dicionário, publicação da qual se espera o máximo de objetividade -, que Mészáros discute a natureza da ideologia. Não sem antes ironizar, afirmando que sentira falta de sinônimos como 'heroico' ou 'santo' na lista de características positivas associadas aos termos conservador e liberal.

A primeira conclusão de Mészáros é indispensável para se pensar a ideologia: “(...) em nossas sociedades tudo está 'impregnado de ideologia', quer a percebamos, quer não" (2004: 57).

Ao se referir ao mundo capitalista liberal-conservador do Ocidente, Mészáros observa que "o discurso ideológico domina a tal ponto a determinação de todos os valores" (2004: 57) que, sem perceber, somos levados a aceitá-los como se fossem expressão da mais pura racionalidade e objetividade - e não fruto de pontos de vista que poderiam ser debatidos ou mesmo refutados com argumentos consistentes, a partir de outro(s) olhar(es).

Para o autor, é evidente que a ideologia dominante tem 'pressupostos ocultos' e 'valores implícitos', cujo rastro tenta esconder. Nas palavras dele, 
Artigo original

Hegemonia - Revista Eletrônica do Programa de Mestrado em Direitos Humanos, Cidadania e Violência/Ciência Política do Centro Universitário Unieuro

ISSN: $1809-1261$

UNIEURO, Brasília, número 24, Julho a Dezembro de 2018, pp. 24-43.

implícitos com que está comprometida a ordem dominante. Assim, em nome da 'objetividade' e da 'ciência', eles precisam desqualificar o uso de algumas categorias vitais do pensamento crítico. Reconhecer a legitimidade de tais categorias seria aceitar o exame dos próprios pressupostos que são assumidos como verdadeiros (...). (2004: 58).

Mészáros dá exemplos de outros termos ou expressões cujo sentido é filtrado ao sabor da ideologia dominante. Cita o caso extremo, relatado pelo escritor norteamericano Harry Magdoff, de um professor de Oxford que escreveu que 'exploração' e 'imperialismo' não seriam palavras usadas por "estudiosos sérios, porque seu significado há muito vem ficando confuso por causa de conceitos ideológicos" (MAGDOFF apud MÉSZÁROS, 2004: 58).

Mészáros chama atenção para a maneira como o referido professor tenta desqualificar ou banir os conceitos de exploração e imperialismo da análise das relações entre países desenvolvidos e países dependentes. Tal procedimento, travestido de cientificismo, cumpre uma função clara: rejeitar de antemão categorias de análise que conceituam de maneira crítica as relações entre nações de capitalismo avançado e nações de economias dependentes.

Acrescentaríamos uma pergunta, ou melhor, uma provocação: a quem interessa isso? O próprio Mészáros responde: o que os defensores do status quo fazem é 'andar em círculos', deduzindo "qualquer coisa que for conveniente à ordem dominante e a sua ideologia oculta" (2004: 58). Em resumo, o que não interessa à ordem vigente ganharia o rótulo de 'conceitos ideológicos confusos', sob a justificativa de uma 'objetividade acadêmica' de dois pesos e duas medidas.

Voltemos a Magdoff e a seu relato sobre o professor de Oxford, bem como ao (pre)conceito de 'estudiosos sérios'. Magdoff, autor de livros sobre imperialismo, rechaça o ponto de vista do professor de Oxford, manifestando estranheza diante de estudiosos que ficam "eriçados apenas contra um certo tipo de palavra" (MAGDOFF apud MÉSZÁROS, 2004: 58). Aqui, Magdoff faz referência a 'imperialismo', a 'exploração imperialista' e a outro vocábulo que nos interessa diretamente neste artigo: 'capitalismo'. Para Magdoff, o capitalismo, "também um termo tão importante do vocabulário socioeconômico", é tratado com 'extrema cautela' pelos 'estudiosos sérios'. (MAGDOFF apud MÉSZÁROS, 2004: 58) 
Artigo original

Hegemonia - Revista Eletrônica do Programa de Mestrado em Direitos Humanos, Cidadania e Violência/Ciência Política do Centro Universitário Unieuro

ISSN: $1809-1261$

UNIEURO, Brasília, número 24, Julho a Dezembro de 2018, pp. 24-43.

III. O poder da ideologia, segundo Mészáros

Mészáros está empenhado em demonstrar como a ideologia dominante usa e abusa da prerrogativa de definir as supostas categorias válidas do pensamento para analisar a realidade de uma época. Assim, além do poder de estabelecer o que teria legitimidade ou não para ser levado a sério no debate intelectual, os representantes da ordem vigente agiriam sem pudor algum, ao classificar sua ideias e sua visão de mundo como objetivas, racionais e neutras - ao passo que qualquer posição desafiadora de seus pressupostos seria automaticamente tachada de ideológica.

A ordem dominante precisa aplicar para si mesma critérios radicalmente diferentes dos aplicados àqueles que devem ser mantidos em sua posição subordinada. Assim, os defensores intelectuais do status quo e guardiães 'neutros' de sua ortodoxia ideológica podem falsear suas autoconfiantes declarações de fé em suas próprias ideias, combinados com ataques violentos a seus adversários, como um 'conhecimento científico' indiscutível, sem se preocupar em apresentar, em favor de suas declarações, nenhuma comprovação extraída das teorias rejeitadas. (MÉSZÁROS, 2004: 60).

Para ilustrar seu raciocínio, Mészáros detém-se, de um lado, nas críticas do economista britânico John Maynard Keynes (1883-1946) a Karl Marx (1818-1883) e, de outro, na relação entre a teoria econômica de Keynes, sua ideologia e um de seus prognósticos.

Mészáros começa atacando o tom adotado por Keynes ao criticar Marx, citando trechos de um texto em que o economista inglês se refere à obra de Marx como 'manual econômico obsoleto', 'cientificamente errôneo' e 'sem interesse ou aplicação para o mundo moderno', por 'preferir a lama ao peixe', ao exaltar o "proletariado rude acima da burguesia e da intelligentsia que, com todas suas falhas, representam a qualidade na vida e certamente carregam as sementes de todo o avanço humano" (KEYNES apud MÉSZÁROS, 2004: 60). 
Artigo original

Hegemonia - Revista Eletrônica do Programa de Mestrado em Direitos Humanos, Cidadania e Violência/Ciência Política do Centro Universitário Unieuro

ISSN: $1809-1261$

UNIEURO, Brasília, número 24, Julho a Dezembro de 2018, pp. 24-43.

De acordo com Mészáros, Keynes demonstra ignorância quanto à obra de Marx, adota um tom de superioridade em relação ao proletariado ou "àqueles que produzem tudo aquilo que a 'qualidade de vida' honradamente expropria para si" e, incrivelmente, consegue ser "aclamado como o grande exemplo de 'objetividade científica' e a refutação final de Marx" (2004: 60). Mészáros descreve o que chama de funcionamento do mecanismo autoprotetor da ideologia dominante: "Obviamente, o pensamento que identifica os próprios desejos com a realidade não tem vergonha nem limites" (2004: 60).

Pelo lado econômico da teoria keynesiana, Mészáros destaca o prognóstico do economista inglês, na década de 1930, de que o problema do 'desemprego tecnológico' faria parte de 'uma fase temporária de desajuste' e que "a longo prazo, a humanidade está solucionando seu problema econômico" (KEYNES apud MÉSZÁROS, 2004: 60). Em fins da década de 1980, porém, o desemprego continuava crescendo, assinala Mészáros, enquanto o 'sermão da fé ideológica' do keynesianismo e de outras visões capitalistas permanecia o mesmo, fazendo referência sempre a uma 'fase temporária de desajuste':

(...) dados os pressupostos necessários de seu ponto de vista social pressupostos que se originam do objetivo consciente e desafiadoramente adotado de defender os direitos adquiridos da 'burguesia educada' -, Keynes fica impedido de perceber o óbvio. Ou seja, a despeito das garantias de seu confortante sermão econômico, não estaremos sequer mais perto da prometida luz no fim do túnel nem daqui a mil anos, pela simples razão de que estamos caminhando na direção oposta, buscando o lucro sob o pretexto da 'utilidade' e destruindo com irresponsável 'eficiência técnica' os mais preciosos recursos humanos e materiais, ao atribuir à cega 'máquina econômica' do capital a tarefa de solucionar o 'problema econômico da humanidade'. (MÉSZÁROS, 2004: 64).

IV. Vitória do capitalismo: fim da ideologia?

Cabe examinar o conceito de ideologia proposto por Mészáros. Em linhas gerais, ele considera a ideologia "uma forma específica de consciência social, materialmente ancorada e sustentada", inerente às sociedades de classes. Nas palavras de 
Artigo original

Hegemonia - Revista Eletrônica do Programa de Mestrado em Direitos Humanos, Cidadania e Violência/Ciência Política do Centro Universitário Unieuro

ISSN: $1809-1261$

UNIEURO, Brasília, número 24, Julho a Dezembro de 2018, pp. 24-43.

Mészáros, a ideologia articula "conjuntos de valores e estratégias rivais que tentam controlar o metabolismo social em todos os seus principais aspectos" (2004: 65).

A questão central tem a ver com a produção e distribuição da riqueza, o que, no capitalismo, esbarra em um conflito estrutural: enquanto a produção é social, a apropriação da riqueza é privada. A partir desse conflito, ou melhor, em torno dele, giram diferentes ideologias cujo cerne consiste em tornar cada indivíduo "praticamente consciente do conflito social fundamental - a partir dos pontos de vista mutuamente excludentes das alternativas hegemônicas que se defrontam em determinada ordem social" (2004: 66). O viés ideológico, portanto, seria inevitável e, ao mesmo tempo, estaria inserido no desenvolvimento social e cultural.

(...) o que se espera das autoimagens da ideologia dominante não é o verdadeiro reflexo do mundo social, com a representação objetiva dos principais agentes sociais e seus conflitos hegemônicos. Antes de tudo, elas devem fornecer apenas uma explicação plausível, a partir da qual se possa projetar a estabilidade da ordem estabelecida.

É por isso que a ideologia dominante tende a produzir um quadro categorial que atenua os conflitos existentes e eterniza os parâmetros estruturais do mundo social estabelecido. (MÉSZÁROS, 2004: 69).

Mészáros menciona a arte, a literatura, a filosofia e a teoria social como reflexos dos desdobramentos ideológicos que atravessam as sociedades. Acrescentaríamos a edição de dicionários.

O livro O poder da ideologia foi originalmente publicado em 1989, ano da queda do muro de Berlim. Em um mundo cindido pela oposição entre capitalismo e socialismo, era o bloco socialista que se esfacelava. O acirrado debate ideológico do qual o dicionário pesquisado por Mészáros era produto - não à toa, made in USA - parecia ter um ganhador, o que abriria caminho, mais uma vez, para o equivocado entendimento de que a própria noção de ideologia poderia ter chegado ao fim.

Mészáros refuta a ideia. Ele afirma que a ideologia é definida por sua época e está vinculada aos conflitos sociais. Logo, em uma sociedade capitalista dividida em classes, não haveria como se falar em fim da ideologia. Mészáros afirma: "Na verdade, proclamar 'o fim da ideologia' é em si uma ideologia característica" (2004: 109). Não custa 
Artigo original

Hegemonia - Revista Eletrônica do Programa de Mestrado em Direitos Humanos, Cidadania e Violência/Ciência Política do Centro Universitário Unieuro

ISSN: $1809-1261$

UNIEURO, Brasília, número 24, Julho a Dezembro de 2018, pp. 24-43.

lembrar o ponto de partida do autor, quando observou que tudo estaria impregnado de ideologia. Nesse caso, até mesmo o seu pretenso fim.

V. Mercadoria, sonho e abstração

O filósofo e cientista social esloveno Slavoj Žižek (1949) joga luz sobre os conceitos de ideologia e capitalismo. Faz isso, traçando um paralelo entre a maneira como Marx descreve a mercadoria - unidade básica do capital - e a interpretação dos sonhos proposta pelo pai da psicanálise, Sigmund Freud (1856-1939).

Tanto na mercadoria quanto no sonho, assinala Žižek, haveria algo oculto. No sonho, o desejo inconsciente ou, mais do que isso, o desafio de compreender como e por que determinado desejo inconsciente assume a forma pela qual é sonhado. $\mathrm{Na}$ mercadoria, a partir do postulado de que seu valor de troca é determinado pela quantidade acumulada de trabalho ao longo de toda a cadeia produtiva, o xis da questão seria compreender por que o trabalho, uma vez tomando a forma de mercadoria, assumiria a condição de valor dessa mercadoria.

Nas palavras de Žižek, o que está em questão "não é o conteúdo oculto pela forma (a forma da mercadoria, a forma do sonho), mas, ao contrário, o 'segredo' dessa própria forma":

O entendimento teórico da forma dos sonhos não consiste em desvendar, a partir do conteúdo manifesto, seu 'cerne oculto', os pensamentos latentes do sonho; consiste na resposta à pergunta: por que os pensamentos latentes do sonho assumiram essa forma, por que foram transpostos para a forma de um sonho? O mesmo acontece com as mercadorias: o verdadeiro problema não é penetrar no 'cerne oculto' da mercadoria - na determinação de seu valor pela quantidade de trabalho consumida em sua produção -, mas explicar por que o trabalho assumiu a forma do valor de uma mercadoria, por que ele só consegue afirmar seu caráter social na forma-mercadoria de seu produto. ( $Z \check{Z} \mathrm{I} Z ̌ E K, 1996:$ 297).

Žižek destaca que os estudos de Marx acerca da forma-mercadoria (1996: 301), objeto do primeiro capítulo do primeiro volume de O Capital, despertaram o 
Artigo original

Hegemonia - Revista Eletrônica do Programa de Mestrado em Direitos Humanos, Cidadania e Violência/Ciência Política do Centro Universitário Unieuro

ISSN: $1809-1261$

UNIEURO, Brasília, número 24, Julho a Dezembro de 2018, pp. 24-43.

interesse de áreas que vão muito além da economia política. De acordo com Žižek, está claro que "há mais em jogo na forma-mercadoria do que a forma-mercadoria em si" (1996: 301).

O ponto-chave seria a abstração que subjaz ao ato da troca. Quando uma mercadoria é negociada, do ponto de vista da efetivação da troca, seu valor de uso pouco importa: sua natureza é abstraída, tendo em vista que o essencial é que a mercadoria tenha o mesmo valor da outra pela qual é trocada.

Assim, no mercado, quando duas mercadorias são negociadas e igualadas em seu valor de troca (seja pelo uso do dinheiro, outra abstração, ou pelo escambo), uma sucessão de relações sociais se condensa e se abstrai (1996: 305).

Žižek observa que os negociantes envolvidos diretamente na troca desconhecem o processo social de produção escondido pela mercadoria. Qual solipsistas, percebendo o mundo como se nada existisse fora de seu universo particular, tomam parte em uma negociação na qual ignoram a trama que deu origem àquela mercadoria. Quando estão em ação no mercado, só enxergam a mercadoria que têm à sua frente, atomizados no ato da troca, sem perceber que essa troca abstrai e condensa o caráter social da produção e sua apropriação privada.

Aqui Žižek relaciona o que Marx chamou de fetichismo da mercadoria - tomar a mercadoria como dotada de vida própria, ignorando as relações sociais de produção por trás dela - com o processo de formação e constituição da ideologia.

Não ter consciência do que está envolvido na troca de mercadorias seria constitutivo do próprio ato da troca. Na mesma linha, ignorar a ideologia que estrutura nossa percepção da realidade seria um pressuposto de nossa consciência social. Dito de outra forma: tomar consciência da realidade implicaria adotar uma forma de perceber o mundo já impregnada de ideologia, na medida em que a visão de mundo que cada indivíduo desenvolve viria acompanhada, em larga medida, de um vasto desconhecimento acerca das relações que estruturam o mundo e a vida em sociedade. A ideologia, portanto, não poderia ser equiparada a uma falsa consciência da realidade. Ideológica seria a própria forma como se estrutura a percepção da realidade. Eis o que Žižek conclui:

Essa, provavelmente, é a dimensão fundamental da 'ideologia': a ideologia não é simplesmente uma 'falsa consciência', uma representação ilusória da realidade; antes, é essa mesma realidade que já deve ser concebida como 'ideológica': 
Artigo original

Hegemonia - Revista Eletrônica do Programa de Mestrado em Direitos Humanos, Cidadania e Violência/Ciência Política do Centro Universitário Unieuro

ISSN: $1809-1261$

UNIEURO, Brasília, número 24, Julho a Dezembro de 2018, pp. 24-43.

'ideológica' é uma realidade social cuja própria existência implica o não-conhecimento de sua essência por parte de seus participantes, ou seja, a efetividade social cuja própria reprodução implica que os indivíduos 'não sabem o que fazem'. 'Ideológica' não é a 'falsa consciência' de um ser (social), mas esse próprio ser, na medida em que ele é sustentado pela 'falsa consciência'. Chegamos finalmente à dimensão do sintoma, pois, uma de suas definições possíveis seria, igualmente, 'uma formação cuja própria consistência implica um certo não-conhecimento por parte do sujeito': o sujeito só pode 'gozar com seu sintoma' na medida em que sua lógica lhe escapa - a medida do sucesso da interpretação do sintoma é, precisamente, sua dissolução.

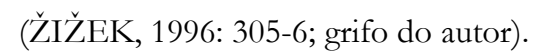

Žižek resume assim a sua definição do que seria ideologia: "O nível fundamental da ideologia, entretanto, não é de uma ilusão que mascare o verdadeiro estado de coisas, mas de uma fantasia (inconsciente) que estrutura nossa própria realidade social" (1996: 316). Em outro trecho, ele detalha e aprofunda essa mesma concepção:

\footnotetext{
Uma ideologia só 'nos pega' para valer quando não sentimos nenhuma oposição entre ela e a realidade - isto é, quando a ideologia consegue determinar o modo de nossa experiência cotidiana da própria realidade. (...) Uma ideologia logra pleno êxito quando até os fatos que à primeira vista a contradizem começam a funcionar como argumentos a seu favor (ŽIŽ̌EK, 1996: 326).
}

A maior força da ideologia é parecer que não existe. A ideologia mostrase como 'ordem natural'.

VI. O sentido oculto do capitalismo

Uma vez que a ideologia está em tudo, é interessante notar como ela se articula em relação ao capitalismo, enquanto representação desse sistema econômico e social.

Žižek, como Mészáros, faz referência ao desequilíbrio estrutural do capitalismo: embora a produção de riquezas (resultado de trabalho coletivo) seja social, sua apropriação é privada (individual). 
Artigo original

Hegemonia - Revista Eletrônica do Programa de Mestrado em Direitos Humanos, Cidadania e Violência/Ciência Política do Centro Universitário Unieuro

ISSN: $1809-1261$

UNIEURO, Brasília, número 24, Julho a Dezembro de 2018, pp. 24-43.

A exploração dos trabalhadores pelos donos dos meios de produção seria inerente ao capitalismo, tendo sua expressão na mais-valia - parcela da riqueza produzida pelo trabalhador que não é remunerada pelo salário, mas, ao contrário, apropriada pelo dono do meio de produção.

Žižek evita um julgamento moral do modo de produção capitalista. Em vez disso, ele perscruta a história e as engrenagens do sistema capitalista, atento à transição da economia feudal para a economia burguesa.

No feudalismo, prevalecia um tipo de produção artesanal em que os próprios donos dos meios de produção vendiam suas mercadorias. As trocas se davam com base no princípio da equivalência, ou seja, a mercadoria A tinha igual valor de troca que a B ou que sua expressão monetária. Foi com o advento da burguesia e da produção orientada para o mercado que, nas palavras de Žižek, surgiu "um novo tipo paradoxal de mercadoria: a força de trabalho" (1996: 307; grifo nosso).

O paradoxo está no fato de que a força de trabalho, além de converterse em mercadoria, passou, ela própria, a ser fonte de mais-valia. Isso porque, mesmo sendo devidamente remunerada, a força de trabalho é capaz de produzir riqueza em volume ainda maior do que a remuneração que enseja. Nas palavras de Žižek, não se trata de uma 'violação', mas de algo estritamente interno à 'troca de equivalentes' no mercado capitalista:

\begin{abstract}
(...) a força de trabalho não é 'explorada' no sentido de seu pleno valor não ser remunerado; em princípio, pelo menos, a troca entre o trabalho e o capital é plenamente equivalente e equitativa. O problema é que a força de trabalho é uma mercadoria peculiar, cujo uso - o trabalho em si - produz uma certa maisvalia, e esse excedente que ultrapassa o valor da própria força de trabalho é apropriado pelo capitalista. (ŽIŽEK, 1996: 307)
\end{abstract}

Para Žižek, portanto, o capitalismo conteria em si uma 'fissura' que seria não só insuperável, mas também constitutiva do modo de produção capitalista (1996: 306). Esse segredo ou 'ponto de ruptura', revelado pela crítica marxista, desmentiria a suposta universalidade de valores apregoados pela ideologia dominante, a começar pela liberdade burguesa em suas variadas formas: de imprensa, de consciência, comercial, política. A tese é clara: o que se apresenta como de interesse universal, na verdade, estaria a serviço da classe burguesa e da reprodução do capital. 
Artigo original

Hegemonia - Revista Eletrônica do Programa de Mestrado em Direitos Humanos, Cidadania e Violência/Ciência Política do Centro Universitário Unieuro

ISSN: $1809-1261$

UNIEURO, Brasília, número 24, Julho a Dezembro de 2018, pp. 24-43.

Mais do que isso, os ditos valores universais do capitalismo conviveriam, dentro do sistema, com a sua própria negação. No centro da incompatibilidade entre os valores ideológicos que o capitalismo apregoa e sua prática constitutiva figuraria a liberdade assegurada ao trabalhador de vender sua força de trabalho, conforme assinala Žižek: "(...) ao vender 'livremente' sua força de trabalho, o trabalhador perde sua liberdade - o conteúdo real desse livre ato de venda é a escravização do trabalhador ao capital" (1996: 306; grifo do autor). Em outras palavras, o que se apresenta como expressão de liberdade estaria, de fato, a serviço da exploração.

VII. Abrindo dicionários: algumas observações

Não é preciso ler as definições de capitalismo e comunismo em alguns dos principais dicionários brasileiros para que uma primeira diferença salte aos olhos: a desproporção do espaço dedicado a um e a outro. No Dicionário Honaiss da Lingua Portuguesa, o número de linhas destinadas ao comunismo ${ }^{3}$ (47) supera em mais de quatro vezes as

\footnotetext{
${ }^{3}$ Num grupo unificado de membros que vivam e trabalhem juntos, sistema de vida em comum em que os bens são partilhados, estando disponíveis segundo as necessidades de cada um $<_{0}$ c. da igreja cristã primitiva $>2$ ECON POL organização socioeconômica baseada no sistema de propriedade coletiva dos meios de produção e na distribuição da riqueza segundo as necessidades de cada um 3 POL doutrina econômica e política que preconiza tal organização 4 ECON POL organização econômica e sociopolítica do Estado, idealizada por Karl Marx e Friedrich Engels (e por seus inúmeros precursores), que, como último estágio da evolução social e como resultado do triunfo das lutas do proletariado, será uma sociedade ideal, sem classes, sem propriedade privada sobre os meios de produção, com harmônica igualdade social e econômica para todos, sendo que os bens, que nessa fase serão produzidos em abundância, pois não haverá estruturas arcaicas que impeçam o constante desenvolvimento das forças produtivas, serão distribuídos segundo as necessidades de cada um (De cada um segundo sua capacidade; a cada um, segundo suas necessidades") 5. POL impr. sistema político, econômico e social em vigor na União Soviética depois da Revolução russa de 1917 e num certo número de outros países denominados repúblicas democráticas ou repúblicas populares, até o final da década de 1980, que seguiam a sua linha; bolchevismo; marxismoleninismo cf. socialismo e socialismo real 6. POL pej. sistema totalitário e ateu no qual o Estado detém a totalidade das indústrias, comércio, meios de transporte, bancos e controla em larga medida, através de um partido político único, a vida social, cultural e econômica de todos os cidadãos - p.opos. a democracia 7. p. ext. POL $p e j$. atividade ou tendência subversiva, fortemente esquerdista 8 . met. POL o conjunto dos comunistas, suas organizações, sua ação política $<$ luta da direita contra o c.> c. primitivo POL SOC organização social típica das culturas da Idade da Pedra, quando o nível de desenvolvimento das forças produtivas é ainda muito baixo, sendo os indivíduos nessa etapa basicamente caçadores, coletores, agricultores incipientes, e ainda não teve começo o processo de divisão das classes; os meios de produção (terra, águas, instrumentos de trabalho) são coletivos e o produto do trabalho é dividido igualmente pelos membros do grupo [Nesse tipo de sociedade viviam os índios americanos quando os europeus aqui chegaram, e alguns ainda vivem assim.] c. revolucionário ECON POL regime que se instala após uma revolução comunista que derruba a classe dos detentores dos meios de produção (capitalistas e latifundiários) e seus defensores (militares, religiosos, políticos e intelectuais reacionários), e inicia a construção de uma sociedade sem classes, eliminando paulatinamente as estruturas arcaicas e despertando a consciência do novo cidadão ETIM comun(i)- + -ismo, prov. por infl. do fr. communisme (1840); f.hist. 1871 communismo .
} 
Artigo original

Hegemonia - Revista Eletrônica do Programa de Mestrado em Direitos Humanos, Cidadania e Violência/Ciência Política do Centro Universitário Unieuro

ISSN: $1809-1261$

UNIEURO, Brasília, número 24, Julho a Dezembro de 2018, pp. 24-43.

linhas consumidas pela definição de capitalismo ${ }^{4}(9)$. No Novo Dicionário Aurélio da Língua

Portuguesa, são 12 linhas (comunismo ${ }^{5}$ ) a 4 (capitalismo ${ }^{6}$ ). No Aulete Digital, na aba 'verbete atualizado', 16 (comunismo $^{7}$ ) a 6 (capitalismo $\left.{ }^{8}\right)$

À primeira vista, tamanha diferença desperta curiosidade, uma vez que o capitalismo é o modo de produção hegemônico no Brasil e no mundo contemporâneo.

Ou seja, as relações econômicas e sociais de praticamente todo o planeta se assentam em bases capitalistas. Mas, ao expor os significados de capitalismo, os três dicionários são 'econômicos' - tanto no sentido de priorizar aspectos ligados à economia quanto no de exercitar o poder de síntese, em grau extremo.

Tal observação faz ecoar a assertiva do escritor norte-americano Harry Magdoff, citado por Mészáros e ao qual fizemos referência anteriormente. Magdoff chama atenção para a 'extrema cautela' com que o termo capitalismo seria tratado. Cabe a pergunta: nos casos específicos analisados neste artigo, o que chamamos de 'poder de ${ }^{4}$ ECON sistema econômico baseado na legitimidade dos bens privados e na irrestrita liberdade de comércio
e indústria, com o principal objetivo de adquirir lucro 2 ECON SOC sistema social em que o capital está em
mãos de empresas privadas ou indivíduos que contratam mão-de-obra em troca de salário 3. p.met. conjunto
de indivíduos, países etc. capitalistas $<0$ c. mundial $<0$ c. integrante do G-7> c. de Estado ECON SOC
envolvimento direto do Estado nos setores produtivos e de serviços ETIM capital s.m. + -ismo; ver capit-.
${ }^{5}$ Qualquer sistema econômico e social baseado na propriedade coletiva. 2. Sistema social, político e
econômico desenvolvido teoricamente por Karl Marx [v. marxismo], e proposto pelos partidos comunistas
como etapa posterior ao socialismo. Qualquer doutrina social, política e econômica que proponha alguma
forma de propriedade coletiva dos meios de produção. 4 . Política ou doutrina dos partidos comunistas. 5. O
conjunto dos comunistas, suas organizações, seu programa e sua atuação política. [Cf. castrismo, leninismo,
marxismo-leninismo, maoísmo, stalinismo e trotskismo.]
${ }^{6}$ Sistema social fundado na influência ou predomínio do capital; regime social em que os meios de produção
constituem propriedade privada e pertencem aos capitalistas.
${ }^{7}$ Sistema social no qual não existe propriedade privada individual, a terra e os meios de produção pertencem
à coletividade, e os bens são partilhados de acordo com as necessidades de cada um.
2. Econ. Pol. Ideologia e doutrina política (concebido por Karl Marx) que visa ao comunismo (1) como
sistema social e econômico a se desenvolver a partir do socialismo, baseado na propriedade coletiva através
do Estado, que se propõe a distribuir os bens segundo as necessidades individuais e a abolir as classes sociais.
3. Econ. Pol. Sistema político, econômico e social que segue o comunismo (2), instaurado na antiga União
Soviética a partir da Revolução de 1917 (onde prevaleceu até 1990), e em alguns outros países.

4. Pol. O conjunto dos comunistas e sua atividade política.

5. Pol. A doutrina e a linha política dos partidos comunistas.

[F.: Do fr. communisme.]

Comunismo

primitivo

1 Hist. Econ. Pol. Sistema de organização social da Idade da Pedra, no qual a propriedade dos meios de produção (relativos à caça, á coleta e a uma agricultura primitiva) eram coletivos, e os produtos divididos entre todos os membros da coletividade.

8 Econ. Sistema econômico e social baseado na propriedade privada dos meios de produção, na subordinação do trabalho (adquirido em troca de salários) ao capital (que é investido para gerar lucro), e na livre concorrência entre agentes (empresas, indivíduos) no mercado.

2. Conjunto mais ou menos integrado de países (e seus mercados, suas instituições, legislações, firmas etc.) em que vigora o sistema capitalista

[F.: capital (subst.) + -ismo.]. 
Artigo original

Hegemonia - Revista Eletrônica do Programa de Mestrado em Direitos Humanos, Cidadania e Violência/Ciência Política do Centro Universitário Unieuro

ISSN: $1809-1261$

UNIEURO, Brasília, número 24, Julho a Dezembro de 2018, pp. 24-43.

síntese' dos dicionários também poderia ser entendido como expressão de cautela ou, melhor ainda, como um quase deliberado propósito de evitar a abordagem de determinadas características do capitalismo?

Os três dicionários fornecem uma pista interessante para se pensar as diferenças de tamanho nas definições atribuídas a um verbete e ao outro. Ao tratar de comunismo, os três citam Marx, como seu idealizador - o Honaiss menciona também Friedrich Engels (1820-1895), coautor do Manifesto do Partido Comunista, e os "inúmeros precursores" de Marx e Engels. À exceção do Aurélio, os outros dois dicionários fazem referência à revolução russa de 1917, bem como ao chamado comunismo primitivo da Idade da Pedra, quando a produção era coletiva e a divisão de bens, igualitária.

Vejamos um dos significados atribuídos pelo Aulete Digital ao comunismo:

3. Econ. Pol. Sistema político, econômico e social que segue o comunismo (2), instaurado na antiga União Soviética a partir da Revolução de 1917 (onde prevaleceu até 1990), e em alguns outros países. (AULETE, 2018).

E um dos significados atribuídos pelo Houaiss ao comunismo:

5. POL impr. sistema político, econômico e social em vigor na União Soviética depois da Revolução russa de 1917 e num certo número de outros países denominados repúblicas democráticas ou repúblicas populares, até o final da década de 1980, que seguiam a sua linha (...). (HOUAISS, 2001: 782).

É digno de nota que, nos significados de capitalismo, a situação é outra: não há menção a períodos, fatos históricos nem 'idealizadores'. Enquanto as definições de comunismo têm a preocupação de apontar referências que minimamente situem o comunismo no tempo e no espaço, o verbete capitalismo não é objeto da mesma preocupação. Nenhum dos três dicionários pesquisados faz qualquer registro da revolução industrial ou da transição do feudalismo para o mercantilismo e o capitalismo.

Não seria exagero dizer que o capitalismo é apresentado como sistema sem passado, sem história. 
Artigo original

Hegemonia - Revista Eletrônica do Programa de Mestrado em Direitos Humanos, Cidadania e Violência/Ciência Política do Centro Universitário Unieuro

ISSN: $1809-1261$

UNIEURO, Brasília, número 24, Julho a Dezembro de 2018, pp. 24-43.

No Aurélio, nem mesmo o adjetivo 'econômico' é empregado para definir o capitalismo. Detalhe: a descrição é tão sucinta que o texto não chegou sequer a ser numerado. Vejamos como o Aurélio define o capitalismo:

Sistema social fundado na influência ou predomínio do capital; regime social em que os meios de produção constituem propriedade privada e pertencem aos capitalistas. (AURÉLIO, 1986: 343).

A estreiteza das definições de capitalismo chama atenção de quem reflete sobre o alcance desse sistema econômico e social. O jurista Fábio Konder Comparato, em artigo intitulado 'Capitalismo: civilização e poder', destaca o poder transformador do capitalismo e sua capacidade de influenciar o modo de vida em todo o planeta. Para Comparato, a humanidade estaria configurada de tal maneira neste século XXI que "todos os povos da Terra, em maior ou menor grau, participam da mesma civilização: a capitalista" (2011: 251).

Convencido de que se trata de momento inédito na história da civilização, Comparato entende que boa parte da humanidade ainda ignora o alcance e o papel desempenhado pelo capitalismo, como sistema instituidor de um modo de vida em escala global. Assim, afora o fato de que se trataria de fenômeno recente, consolidado nas últimas décadas, o motivo para tamanha 'inconsciência coletiva' seria outro. Nas palavras de Comparato,

A segunda razão, pela qual uma boa parte da humanidade ainda não tomou consciência desse fato histórico sem precedentes, é que, fora do círculo intelectual marxista, o capitalismo sempre foi apresentado, pura e simplesmente, como um sistema econômico; e boa parte dos economistas o analisava, e continua a analisá-lo, na esteira dos fisiocratas franceses que influenciaram Adam Smith, como o único sistema natural da vida econômica. Creio chegado o momento de se compreender o fenômeno, ou seja, de se tomar o capitalismo em toda a sua riqueza de sentidos (cum prehendere); vale dizer, antes de mais nada, como uma autêntica civilização, usando esse conceito em sentido eticamente neutro. (COMPARATO, 2011: 251). 
Artigo original

Hegemonia - Revista Eletrônica do Programa de Mestrado em Direitos Humanos, Cidadania e Violência/Ciência Política do Centro Universitário Unieuro

ISSN: $1809-1261$

UNIEURO, Brasília, número 24, Julho a Dezembro de 2018, pp. 24-43.

VIII. Capitalismo selvagem (e os significados pejorativos)

Retornando às páginas dos dicionários, nota-se que o Houaiss registra dois significados pejorativos para o comunismo, o que não se verifica em relação ao capitalismo. Nos demais dicionários pesquisados, não foram constatados significados depreciativos em nenhum dos verbetes. Eis os registros pejorativos do Houaiss para comunismo:

6. POL pej. sistema totalitário e ateu no qual o Estado detém a totalidade das indústrias, comércio, meios de transporte, bancos e controla em larga medida, através de um partido político único, a vida social, cultural e econômica de todos os cidadãos. (...)

7. p. ext. POL pej. atividade ou tendência subversiva, fortemente esquerdista. (HOUAISS, 2001: 782)

Um dos significados tidos como pejorativos para comunismo 'atividade ou tendência subversiva, fortemente esquerdista' - suscita uma questão: por que o Houaiss, no verbete capitalismo, não faz referência à associação desse termo com tendências 'liberais', 'conservadoras' ou 'direitistas'? Aqui parece residir uma questão que mereceria aprofundamento nas pesquisas sobre ideologia e suas ramificações: enquanto o comunismo é apresentado como tendência atrelada a um lado do espectro ideológico - a esquerda -, o capitalismo não é associado a nenhum grupo ou viés ideológico. Qual a explicação para tal diferença: o entendimento de que o capitalismo pairaria acima das questões ideológicas? Ou de que o capitalismo, enquanto sistema econômico e social, seria uma roupagem capaz de vestir indistintamente ideias de esquerda, de centro ou de direita, de maneira que não faria sentido atrelá-lo a um viés específico?

A inexistência de significados pejorativos para capitalismo causa estranheza, visto que a palavra é usada com sentido negativo, em acepções bastante populares na cultura brasileira. É o caso da expressão capitalismo selvagem, que traça um paralelo entre as durezas da vida na selva e as disputas no mundo dos negócios. A expressão ganhou notoriedade na década de 1980, com a música Homem Primata, da banda de rock Titãs. Eis um trecho da letra: 
Artigo original

Hegemonia - Revista Eletrônica do Programa de Mestrado em Direitos Humanos, Cidadania e Violência/Ciência Política do Centro Universitário Unieuro

ISSN: $1809-1261$

UNIEURO, Brasília, número 24, Julho a Dezembro de 2018, pp. 24-43.

\begin{tabular}{|c|c|c|c|c|c|c|c|}
\hline $\mathrm{Eu}$ & & & & & & & aprendi \\
\hline A & & vida & é & & um & & jogo \\
\hline Cada & & um & & & por & & si \\
\hline E & & Deus & & & & & todos \\
\hline Você & vai & morrer & $\mathrm{e}$ & não & vai & pro & cé \\
\hline É & bom & aprender, & & a & vida & é & cru \\
\hline Home & & & & & & & primata \\
\hline
\end{tabular}

Comparato enfatiza a desumanização provocada pelo capitalismo. Resgatando a história do desenvolvimento capitalista, ele lembra que a operação de comércio - a compra e revenda - gira em torno do lucro. Que, no capitalismo, tudo se transforma em mercadoria, inclusive os seres humanos.

Comparato define assim a desumanização intrínseca ao capitalismo:

Desumanizar a vida significa excluir da biosfera o seu centro de valor universal: a pessoa humana. Cada um de nós é um ser único, insubstituível e irreprodutivel. A descoberta do DNA veio demonstrá-lo. Ora, o sistema de relacionamento capitalista é essencialmente impessoal. Vivemos, cada vez mais, em um mundo de organizações artificiais sem nome, nas quais desaparece inteiramente a figura humana. Não é, pois, por simples coincidência histórica se uma das principais criações do engenho mercantil capitalista é a sociedade anônima.

(...) Nas macroempresas capitalistas, ninguém sabe, a rigor, quem é o controlador, pois as participac,ões de capital, diretas ou cruzadas, constituem um emaranhado ou uma cadeia sem fim. Foi preciso, pois, contrariando um dogma jurídico de muitos séculos, criar uma responsabilidade penal da pessoa jurídica; como ocorreu entre nós com a promulgação da Lei n. 9.605, de 12 de fevereiro de 1998, relativa a condutas e atividades lesivas ao meio ambiente. (COMPARATO, 2011: 256).

Fica a suspeita de que não é por falta de defeitos ou problemas reais que o capitalismo aparece destituído de significados depreciativos em dicionários. 
Artigo original

Hegemonia - Revista Eletrônica do Programa de Mestrado em Direitos Humanos, Cidadania e Violência/Ciência Política do Centro Universitário Unieuro

ISSN: $1809-1261$

UNIEURO, Brasília, número 24, Julho a Dezembro de 2018, pp. 24-43.

IX. Pluralidade: uma saída

Os dicionários Houaiss e Aulete mencionam a palavra lucro, na definição de capitalismo. O Houaiss informa que o principal objetivo no capitalismo é 'adquirir lucro', acepção que não consta no Aurélio. Nenhum dos três dicionários, porém, faz referência à exploração inerente ao capitalismo. No Houaiss, empresas ou indivíduos "contratam mão-de-obra em troca de salário" (2011: 611). Nesse sentido, o que mais se aproxima é o Aulete Digital, com a seguinte definição:

1. Econ. Sistema econômico e social baseado na propriedade privada dos meios de produção, na subordinação do trabalho (adquirido em troca de salários) ao capital (que é investido para gerar lucro), e na livre concorrência entre agentes (empresas, indivíduos) no mercado. (AULETE, 2018; grifo nosso).

O economista Paulo Sandroni, organizador do Dicionário de Economia, traça um panorama bem mais diversificado, ao discorrer sobre o capitalismo. Por se tratar de obra especializada, não chega a ser uma surpresa. Ainda assim, vale o registro de como Sandroni consegue apresentar uma visão mais completa desse complexo sistema econômico e social atualmente hegemônico.

Primeiro, Sandroni cita três autores que analisaram o assunto, pinçando uma ou outra ideia central de cada autor. De Werner Sombart (1863-1941), é realçado que a essência do capitalismo não estaria na economia, "mas no 'espírito' que se desenvolveu dentro da burguesia que surgiu na Europa no fim da Idade Média" (1989: 37). De Max Weber (1864-1920), um dos fundadores da sociologia, é feita referência ao papel da burocracia na crescente profissionalização das empresas, em busca do lucro. De Marx, é apresentada a ideia de que a definição do capitalismo seria "a exploração dos trabalhadores pelos capitalistas" (1989: 37).

Em segundo lugar, Sandroni resume parte da história do capitalismo, observando que, já a partir do século XIII, o enriquecimento da burguesia deu início à criação de bancos e à prática do comércio em grande escala, principalmente em portos do norte da Itália e do mar do Norte (localizado no Oceano Atlântico, no norte europeu). A revolução industrial teve lugar na Inglaterra, nos séculos XVIII e XIX, com a mecanização da produção industrial. 
Artigo original

Hegemonia - Revista Eletrônica do Programa de Mestrado em Direitos Humanos, Cidadania e Violência/Ciência Política do Centro Universitário Unieuro

ISSN: $1809-1261$

UNIEURO, Brasília, número 24, Julho a Dezembro de 2018, pp. 24-43.

Por fim, Sandroni descreve algumas das características do capitalismo observadas já no fim do século XIX e ao longo do século XX:

\begin{abstract}
No final do século [XIX], acentuavam-se as tendências à concentração, com cartéis, trustes e monopólios, o que, no século XX, resultaria na formação de gigantescas empresas multinacionais. Para elas, o planejamento a longo prazo é fundamental, devido à tendência à diminuição da taxa de lucro. As crises são frequentes, provocando falências, desemprego e inflação em boa parte do mundo. Para amenizar essas crises, é crescente a intervenção do Estado na Economia. (SANDRONI, 1989: 37).
\end{abstract}

Como demonstra Sandroni, há caminhos para que os dicionários superem eventuais barreiras ideológicas e enriqueçam as definições de conceitos complexos e plurais. Seria um ganho para a formação das novas gerações.

Referências bibliográficas

AULETE Digital. (2018). Disponível em: <http://www.aulete.com.br>. Acesso em: 26 jan.

COMPARATO, Fábio Konder. (2011). 'Capitalismo: civilização e poder’. In: Estudos Avançados, vol. 25, $n^{\circ}$ 72, MailAgo. São Paulo: Instituto de Estudos Avançados da Universidade de São Paulo.

FERREIRA, Aurélio Buarque de Holanda. (1999). Novo Aurélio Século XXI: o dicionário da lingua portuguesa. $3^{a}$ edição. Rio de Janeiro: Nova Fronteira.

HOUAISS, Antônio. (2001). Dicionário Houaiss da Língua Portuguesa. Rio de Janeiro, Ed. Objetiva.

MÉSZÁROS, István. (2014). O poder da ideologia. Tradução de Magda Lopes e Paulo Cezar Castanheira. São Paulo: Boitempo.

SANDRONI, Paulo (org.). (1989). Dicionário de Economia. São Paulo: Editora Best Seller. ŽIŽEK, Slavoj. (1996). ‘Como Marx inventou o Sintoma?’. In: ŽIŽEK, Slavoj (org.). Um mapa da ideologia. Rio de Janeiro: Contraponto Editora. 